\title{
Effects of Sudanese Dromedary's Camel Raw Milk on Insulin Doses and Carbohydrate Metabolism in Type 1 Diabetic Patients
}

\section{Kamal Omer Abdalla ${ }^{*}$ and Ahmed Abdalla Fadlalla ${ }^{2}$}

${ }^{1}$ Department of Biochemistry, Faculty of Medicine and Health Sciences, University of Gadarif, Sudan

${ }^{2}$ Department of Pediatrics, Faculty of Medicine \& Health Sciences, University of Gadarif, Gadarif Pediatrics' Teaching Hospital, Sudan

\begin{abstract}
The efficacy of Sudanese Camel dromedary's raw milk on insulin doses, fasting and postprandial blood sugars and glycated hemoglobin ( $\mathrm{HbA1c}$ ) in 30 type 1 diabetic patients have been evaluated for 12 months. Baseline data for all the patients were similar in demographic characteristics and variables. After two-month monitoring period, the patients were randomly divided into two groups. Control group ( $\mathrm{N}=15$ patients), received usual medical care i.e. health advices, diet, exercise and insulin, and study group (also $\mathrm{N}=15$ patients), received the same medical care as for group 1, in addition to $0.5 \mathrm{~L} /$ day of raw dromedary's camel milk that was consumed by $250 \mathrm{ml}$ twice/day in the morning and evening. Camel milk has caused significant reduction in insulin dosages necessary to obtain euglycemia by $46 \%$ (from $75.80 \pm 25.5$ units/day to $42.75 \pm 22.5$ units/day; $\mathrm{P}<0.0002$ ), fasting blood sugar was reduced by $67 \%$ (from $286 \pm 108 \mathrm{mg} / \mathrm{dl}$ to $95 \pm 22 \mathrm{mg} / \mathrm{dl}$; $\mathrm{P}<0.0001$ ), postprandial blood sugar was reduced by $65 \%$ (from $264 \pm 136$ $\mathrm{mg} / \mathrm{dl}$ to $93.5 \pm 17.5 \mathrm{mg} / \mathrm{dl} ; \mathrm{P}<0.0001$ ) and $\mathrm{HbA} 1 \mathrm{c}$ was reduced by $37 \%$ (from $7.3 \pm 2.9 \%$ to $4.6 \pm 1.5 \% ; \mathrm{P}<0.0001$ ). This was in contrast to the control group as all their clinical parameters have been remained unchanged unless received high doses of parenteral insulin. In conclusion, this study has proven that, dromedary's camel milk works well in regulation of blood sugar and improvement of carbohydrate metabolism in type 1 diabetic patients in the absence of original insulin when is given as an adjuvant to insulin therapy. It seems that dromedary's camel milk works well with the body's own restorative and regenerative abilities to overcome any metabolic aberrations in carbohydrate metabolism that might resulted from diabetes mellitus. Camel milk is well tolerated, it has no any hypoglycemic risk and it can be used safely by diabetic patients on an empty stomach or after meals. Because of its high nutritional value, preventive and therapeutic qualities against DM and its complications, the authors encourage healthy individuals, people at risk to diabetes and diabetic patients to consume dromedary's camel milk
\end{abstract}

Keywords: Dromedary's camel milk; Diabetes; Treatment

\section{Introduction}

Diabetes mellitus (DM) is one of the most prevalent and serious chronic human disease that has become a major health challenge for all countries of the world [1]. In 2011, the disease affected 366 million people in the world and the number is expected to reach 552 million by 2030 [1]. For instance, DM incidences are in an increase with high prevalence rates in Sudan. The disease is affecting $6 \%$ of the Sudanese population, $70 \%$ of them are not yet aware of their diabetic status and $20 \%-25 \%$ of the patients are suffering the complications of the DM (Sudan Federal Ministry of Health, 2012). DM is a leading cause of mortality, morbidity and economic loss in nearly all countries and it was the cause of death of 4.6 million patients in 2011 [1]. The WHO projects that death from DM will increase by two thirds between 2008 and 2030. Till now, there is no known drug that has shown to modify the course of diabetic complications $[2,3]$. There is a need to search for safer and effective therapies for DM, either as complementary or alternative to existing treatment programs. Moreover, studying of DM is important in order to allocate community and health resources and to encourage measures to counteract trends for its increasing prevalence and complications.

Sudan ranks the second owner of dromedaries' camels' wealth globally-wise with over 4.3 camel heads accordingly to 2010 animal census [4]. In Sudan, camel milk is ample, available everywhere in the country and in reach for everyone. People in Sudan, Africa and the Middle East use dromedary's raw camel milk to treat DM and other human chronic diseases $[2,5,6]$. Studies carried out on dromedary's raw camel milk to explore its effects in the treatment of diabetes mellitus have proven that, dromedary's camel milk was effective in the control of hyperglycemia, improvement of carbohydrate and lipid metabolism, regeneration of damaged beta-cells of the pancreas and zero prevalence of DM among camel nomads who normally consume dromedary's camel milk $[7,8,6]$. In spite of these very striking evidences; very limited studies have been carried out in Sudan to explore the therapeutic qualities of dromedaries' raw camel milk in the management of DM and its complications. Therefore, there is an urgent necessity to conduct baseline studies on the prevalence, geographic distribution, knowledge, attitudes and practices with new modalities of treatment and management relating to DM in Sudan, with the aim to provide a benchmark towards assisting in the development of effective control measures of diabetes and monitoring their implementation. This study has investigated the efficacy of Sudanese dromedary's camel's raw milk on insulin doses necessary to obtain euglycaemia, fasting and postprandial blood sugars and HbAlc in 30 randomly selected type 1 diabetic patients for 12-month period. In this respect, this study is important.

\section{Study Area and the Study Groups}

This study was conducted in Gadarif Pediatrics' Teaching Hospital

*Corresponding author: Kamal Omer Abdalla, Department of Biochemistry, Faculty of Medicine and Health Sciences, University of Gadarif, Sudan, Tel: +249119246534; Fax: +249-4481-42578; E-mail: kamalabdalla03@gmail.com

Received January 08, 2018; Accepted January 29, 2018; Published February 05, 2018

Citation: Abdalla KO, Fadlalla AA (2018) Effects of Sudanese Dromedary's Camel Raw Milk on Insulin Doses and Carbohydrate Metabolism in Type 1 Diabetic Patients. J Biomol Res Ther 7: 159. doi:10.4172/2167-7956.1000159

Copyright: @ 2018 Abdalla $\mathrm{KO}$, et al. This is an open-access article distributed under the terms of the Creative Commons Attribution License, which permits unrestricted use, distribution, and reproduction in any medium, provided the original author and source are credited. 
in Gadarif State that is located in the East of Sudan. All children with diabetes or diabetic complications in the state are referred to this hospital. Thirty type 1 diabetic patients were recruited randomly in this study. Baseline data for all the patients were similar in demographic and variables. Each group consisted of 4 males and 11 females with ages between 8-19 years and period of diabetes onset between 2-15 years. All the patients underwent 2 month period of frequent monitoring of their blood sugar, strict diet, and exercise and insulin treatment. After this period, the patients were again randomly divided into two groups. Control group ( $\mathrm{N}=15$ patients), received usual medical care i.e. heath advices, diet, exercise and insulin, and study group (also $\mathrm{N}=15$ patients), received the same medical care as for group 1 , in addition to $0.5 \mathrm{~L} /$ day of raw dromedaries' camel milk that was consumed by $250 \mathrm{ml}$ twice/ day in the morning and at night. Patients with any acute metabolic complications like hypoglycemia, ketoacidosis, cardiovascular diseases, renal, heart or acute infections were excluded from the study.

The ethical committee of the Faculty of Medicine and Health Sciences, University of Gadarif approved the protocol of the study, and subjects of the study have given oral and written consents before their inclusion in the study. Data collection forms were designed including personal data, clinical data, and laboratory findings.

\section{Materials and Methods}

\section{Study design and analyses}

This is a randomized twelve-month, open case control, parallel design study. Insulin doses were adjusted weekly and whenever necessary, fasting blood sugar, postprandial blood sugar analyses were measured weekly and glycated hemoglobin (HbAlc) was measured every 3 months for 12 month period for all the 30 type $1 \mathrm{DM}$ patients. Any patients who refused to participate in the study or missed during the follow-up have been excluded.

\section{Collection of dromedary's camel milk}

Camel milk samples were collected weekly in the morning from healthy dromedaries' camels that feed on natural grazing in Albutana Rural Area that is located in the North of the Gadarif State. The milk was collected in sterile screw bottles that were kept in cool boxes. On arrival to the hospital, the milk samples were kept in refrigerator and distributed by $0.5 \mathrm{~L} /$ day to each of the 15 members of the study group.

\section{Biochemical investigations}

To assess the effects of the raw dromedaries camel milk on insulin doses and carbohydrate metabolism in the 30 type 1 diabetic patients, the following clinical parameters were followed up: insulin doses were adjusted weekly and when necessary, fasting blood sugar, postprandial blood sugar were measured weekly and $\mathrm{HbAlc}$ was measured every 3 months. All the lab tests were performed in duplicates using blood sera, and the mean values were calculated accordingly. Venous patients' blood samples were drawn in plain tubes (BioSystems, USA), blood samples were left to clot and centrifuged for 5 minutes by 5000/ rpm in REMI centrifuge (China) to obtain the sera. All the lab tests were performed according to the approved protocol of the study. Doses of insulin were prescribed to the patients by the pediatrician by 2-3 separate doses after breakfast, lunch a/o after dinner.

\section{Fasting and post-prandial blood sugar (FBS; PPS)}

Serum fasting and post-prandial sugars were measured once a week in duplicates for 12 months for all the 30 type 1 diabetic patient using glucose kits reagents for measurement of glucose concentration only for in vivo use in the clinical laboratory from BioSystems S.A. (Costa Brava 30, 08030 Barcelona, Spain) by spectrophotometric method.
The measurements were done according to the manufacturer's kit. Biosystems BTS 310 Photometer Chemistry Analyzer (Barcelona, Spain) was used to measure the glucose concentration. Normal values according to this method are: fasting serum sugar $70-110 \mathrm{mg} / \mathrm{dl}$ and serum post-prandial sugar $80-140 \mathrm{mg} / \mathrm{dl}$.

\section{Glycated hemoglobin (HbA1c)}

Whole venous blood glycated hemoglobin (HbA1c) was measured in duplicates at the beginning of the study and every 3 months for 12 months for all the 30 type 1 diabetic patients. HbAlc values were measured using kits reagents for measurement of $\mathrm{HbA} 1 \mathrm{c}$ concentration only for in vivo use in the clinical laboratory from BioSystems S.A. (Costa Brava 30, 08030 Barcelona, Spain) by spectrophotometric method. The measurements were done according to the manufacturer's instructions. Labona Check TMA1c Hblc Analyzer was used to measure the HbAlc concentrations. According to this method: HbAlc values $2-6.5 \%$ normal; in pre-diabetic state $5.7-6.4 \%$; and in diabetic state the values are greater than $6.5 \%$.

\section{Results}

\section{Insulin doses}

The mean value of the insulin doses for the control group at the beginning of the study (month 1 ) was in the range of $56.5 \pm 32.5$ units/ day, while the mean value of the insulin dose for the entire control group from month 7 to 12 was in the range of $74 \pm 41$ units/day. These results have shown an increase to $31 \%$ of the necessary insulin doses to main euglycemia for all individuals of the control group compared to the measurements at the beginning of the study. Figure 1 shows the trends in the insulin doses for the control group.

The mean value of the insulin doses for the study group before consumption of the camel milk was $(75.8 \pm 25.5)$ units/day. While the mean value of the insulin doses for the study group after consumption of the camel milk become $(42.75 \pm 22.5)$ units/day. Statistical analysis of the insulin doses for the study group before and after consumption of the camel milk showed significant difference $(\mathrm{P}<0.0002)$. The results showed an average reduction in the insulin doses necessary to maintain euglycemia for the entire study group after the consumption of the camel's milk by $46 \%$. This was in contrast to the results of the insulin doses for the control group, where insulin doses necessary to maintain euglycemia were in an increase for the entire group. Figures 2 and 3 show trends in the insulin doses before and after camel's milk consumption for the study group.

\section{Results of FBS and PPS}

The mean value of the FBS for the entire control group at the beginning of the study was $(335.5 \pm 158.5) \mathrm{mg} / \mathrm{dl}$ and it continued unchanged. Improvement in FBS for the control group occurred only after continuous an increase in the parenteral insulin doses up to $31 \%$ till month 7 where FBS became $(94.5 \pm 15.5) \mathrm{mg} / \mathrm{dl}$ and remained stable. The mean value of the PPS for the entire control group at the beginning of the study was $(334.5 \pm 149.5) \mathrm{mg} / \mathrm{dl}$. The values of PPS for the control group also remained unchanged. It improved with concomitance with the improvement in the FBS values as a result of continuous an increase in the parenteral insulin doses till month 6 where it became stable with the an average value of $(93.5 \pm 14.5) \mathrm{mg} / \mathrm{dl}$. The measurements of FBS and PPS for the control group were in good correlation with the increased parenteral doses of insulin.

The mean value of the FBS for the entire study group before consumption of the camel milk was $(286 \pm 108) \mathrm{mg} / \mathrm{dl}$, while the mean value of the FBS for the entire study group after consumption 


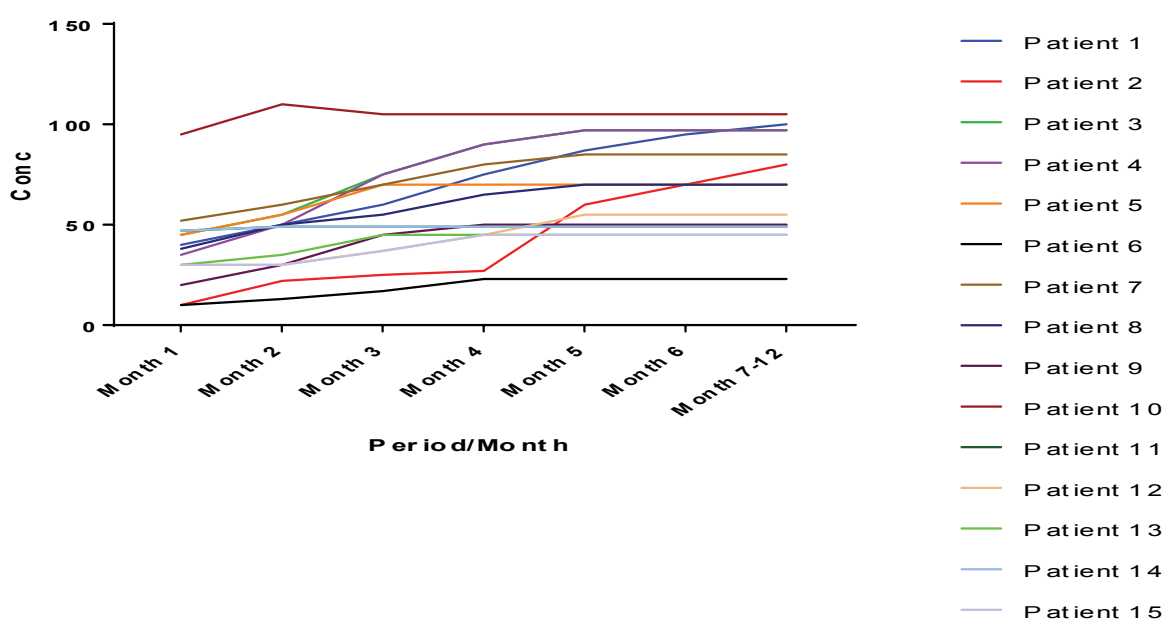

Figure 1: Trends in the insulin doses for the control group.

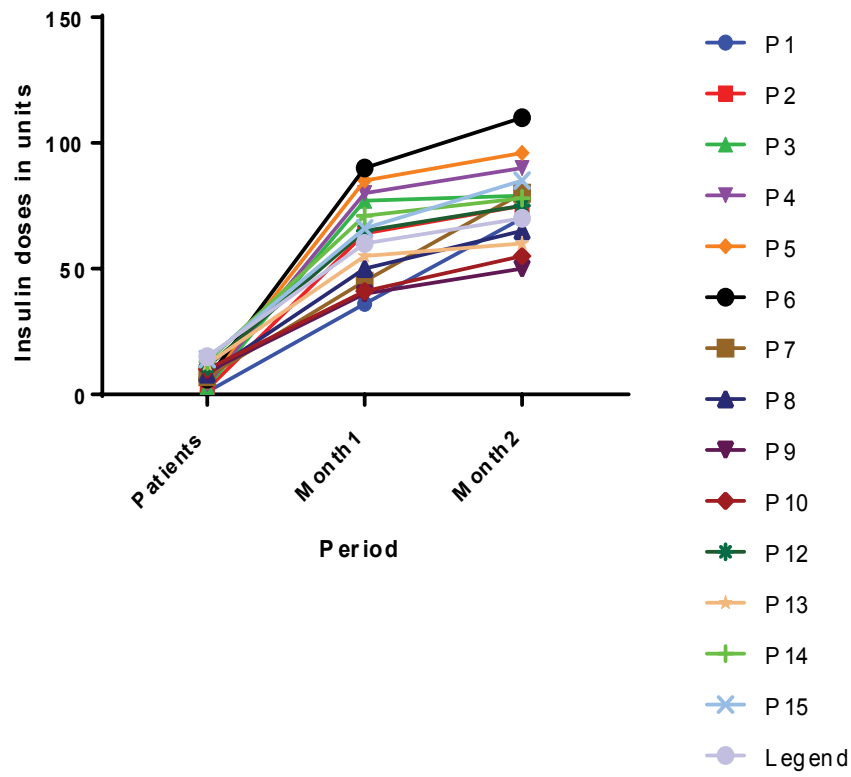

Figure 2: Trends in the insulin doses for the study group before consumption of the dromedary's camel's milk.

of the camel milk was $(95 \pm 22) \mathrm{mg} / \mathrm{dl}$. Analysis of the FBS values for the study group before and after consumption of the camel milk showed significant difference $(\mathrm{P}<0.0001)$. The results showed significant reduction in the FBS for the entire study group by $67 \%$ after consumption of the camel milk. The mean value of the PPS for the entire study group before consumption of the camel milk was $(264 \pm 136) \mathrm{mg} / \mathrm{dl}$, while the mean value of PPS for the entire study group after consumption of the camel milk was $(93.5 \pm 17.5) \mathrm{mg} / \mathrm{dl}$. Statistical analysis of the PPS values for the study group before and after consumption of the camel milk showed significant difference $(\mathrm{P}<0.0001)$. The results showed reduction in the PPS by $65 \%$ for all the study group members after consumption of camel milk.

\section{Results of glycated hemoglobin (HBA1C)}

The mean value of the $\mathrm{HbAlc}$ for the entire control group at the beginning of the study was $(8.15 \pm 0.85) \%$, while the mean value of the $\mathrm{HbA1c}$ for the entire control group during month 6-12 was (5.75 \pm

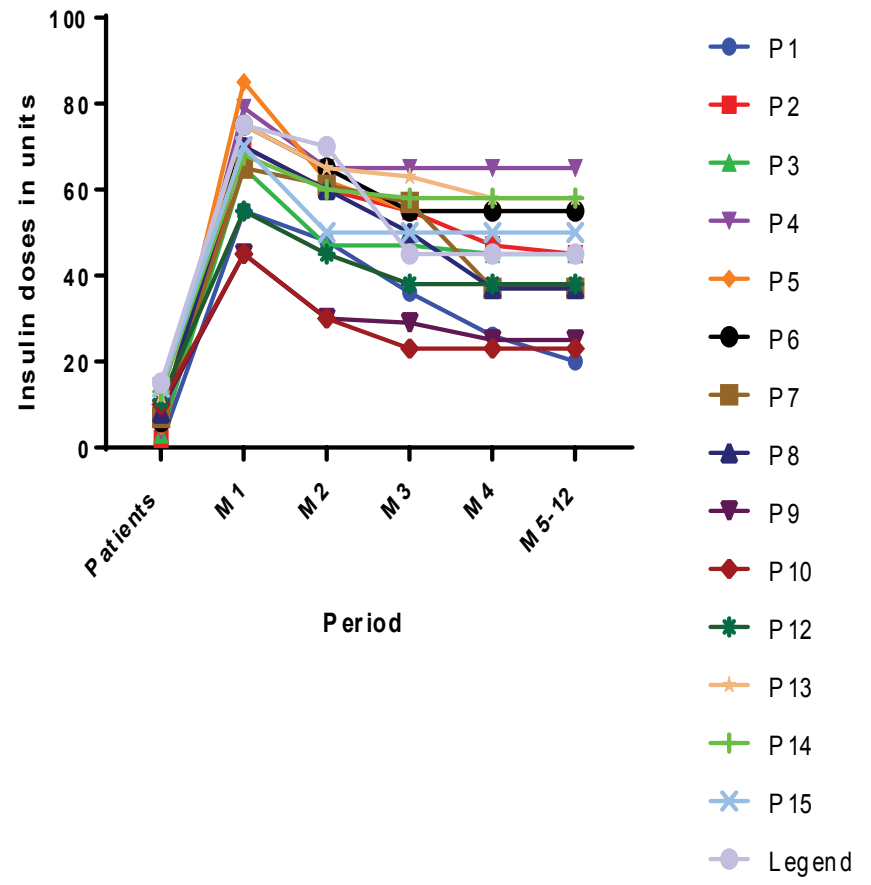

Figure 3: Trends in the insulin doses for the study group after consumption of the dromedary's camel's milk.

0.75)\%. This improvement in the HbAlcl values for the control group was achieved due to increased high doses of parenteral insulin. The results are in good correlations with the increased parenteral insulin doses, FBS and PPS of the control group.

The mean value of the HbAlc for the entire study group before consumption of the camel milk was $(7.3 \pm 2.9) \%$. While the mean value of $\mathrm{HbA1C}$ for the entire study group after consumption of the camel milk was $(4.6 \pm 1.5) \%$. Statistical analysis of the HbAlc values for the study group before and after consumption of the camel milk showed significant difference $(\mathrm{P}<0.0001)$. These results showed reduction in the HbAlc values for the study group by $37 \%$ after consumption of the camel milk. Table 1 summarizes the effects of the raw dromedaries' camel milk on the doses of insulin, FBS, PPS and the HbAcl for the study group. 


\begin{tabular}{|c|c|c|c|c|c|}
\hline No. & Clinical variables & $\begin{array}{c}\text { Clinical variables before } \\
\text { consumption of the camel milk }\end{array}$ & $\begin{array}{c}\text { Clinical variables after consumption } \\
\text { of the camel milk }\end{array}$ & $\begin{array}{c}\boldsymbol{P} \text { value } \\
(42.75 \pm 22.5) \text { units/day }\end{array}$ & $\begin{array}{c}\text { Effects after camel milk consumption } \\
(P<0.0002)\end{array}$ \\
\hline 1 & Insulin dose & $(75.80 \pm 25.5)$ units/day & $(95 \pm 22) \mathrm{mg} / \mathrm{dl}$ & $(P<0.0001)$ \\
\hline 2 & FBS & $(286 \pm 108) \mathrm{mg} / \mathrm{dl}$ & $(93.5 \pm 17.5) \mathrm{mg} / \mathrm{dl}$ & $(P<0.0001)$ & Reduction in insulin doses by $46 \%$ \\
\hline 3 & PPS & $(264 \pm 136) \mathrm{mg} / \mathrm{dl}$ & $(4.6 \pm 1.5) \%$ & $(P<0.0001)$ & Reduction in FBS by $67 \%$ \\
\hline 4 & HbA1c & $(7.3 \pm 2.9) \%$ & in HbA1c by $37 \%$ & \\
\hline
\end{tabular}

Table 1: Summary of the effects of the raw dromedaries' camel milk on the doses of insulin, FBS, PPS and the HbAc1 for the study group.

\section{Discussion}

Type 1 diabetes mellitus results from a cellular-mediated autoimmune destruction of the beta-cells of the pancreas. It can affect children or adults, but it was traditionally termed "juvenile diabetes" because majorities of these diabetes cases were in children [6,7]. Diabetes mellitus interrupts normal child development and carries the threat of severe complications in the active period of children lives [9]. The main treatment of type 1 diabetes mellitus (insulin-dependent diabetes mellitus, IDDM) is insulin replacement via parenteral routes which is far from satisfactory. This is because; injections are painful and not pleasant procedure, especially when are given by 2-3 times/ day throughout the life of the patient. Secondly, many patients have phobia against injections notably children. Thirdly, insulin is expensive to purchase by diabetic patients especially in least income countries like Sudan for example. Fourthly, parenteral insulin is not safe in the long-term of uses as development of anti-insulin antibodies is possible, and lastly, parenteral insulin is associated with the risk of hypoglycemic events and coma if is taken inappropriately $[5,6]$.

To overcome the drawbacks of parenteral insulin therapy, scientists have developed oral insulin, hexyl-insulin monoconjugate-2 (HIM2), in which a single amphiphilic olignmer is covalently linked to the free amino group on the lysine29 residue of recombinant human insulin via an amide bond $[3,10]$. HIM2 alterations in physico-chemical properties are a characteristic which resists the enzymatic degradation and facilitates absorption of the modified insulin. This technological based-oral insulin therapy presumably rated the best treatment, but it has also suffers several drawbacks. First, it takes more time and efforts, it is expensive, and its coagulum formation nature in the stomach due to acidic environment reduces its effectiveness and it is accompanied with constant episodes of abnormally hypoglycemia and gain in weight [11]. Therefore, it is urgently needed to search for safer and more effective medicines for the treatment of DM, either as complementary a/o alternative to existing treatment programs as no known drug has shown to modify the course of diabetic complications. There are no known preventive measures against type 1 diabetes [2]. An alternative to current insulin treatment of IDDM is camel's dromedary's raw milk.

The current study has investigated the effects of Sudanese Camel dromedary's raw milk in doses of insulin, FBS, PPS and HbAlc of type 1 diabetic patients in Gadarif State that is located in the East of Sudan. To achieve this goal, Thirty (30) type 1 diabetic patients were recruited randomly from Gadarif Pediatrics' Teaching Hospital. All the 30 patients followed strict diet, exercise and insulin treatment for 2 months. During this period, frequent monitoring of FBS and PPS were measured in attempts to maintain euglycemia. After this period, the patients were gain randomly divided into two groups. Control group ( $\mathrm{N}=15$ patients), received usual medical care i.e. heath advices, diet, exercise and insulin, and study group (also $\mathrm{N}=15$ patients), received the same medical care as for group 1, in addition to $0.5 \mathrm{~L} /$ day of raw dromedaries' camel milk that was consumed by $250 \mathrm{ml}$ twice/day in the morning and at night. Patients with any acute metabolic complications like hypoglycemia, ketoacidosis, cardiovascular diseases, renal, heart or acute infections were not included in the study.

This study has revealed that camel milk causes significant reduction in insulin dosages in insulin dependent diabetic subjects to obtain glycemic control. Camel's milk has reduced the doses of insulin necessary to maintain euglycemia for the study group by $46 \%$ after 4 months of its uses. The mean dose of insulin/day for the entire study group before consumption of the camel milk was $75.8 \pm 25.5$ units/ day and after consumption of the camel milk, insulin doses became down rapidly initially and then gradually to a mean level of $42.75 \pm 22.5$ units/day. Statistical analysis of the insulin doses for the study group before and after consumption of the camel milk has shown significant difference $(\mathrm{P}<0.0002)$. This is one of the most important findings of the study. These results are in contrast to the results of the subjects not received camel's milk (the control group), where their insulin doses necessary to maintain euglycemia were in an increase for the entire group by $31 \%$. The mean insulin dose for the entire control group at the beginning of the study (month 1 ) for the control group was $56.5 \pm 32.5$ units/day, and then it was in an increase gradually until month seven where it became stable until the end of the study (month 12); $74 \pm 41$ units/day. This might be explained by the fact that, Camel dromedaries milk contains high concentration of insulin i.e. 52-59 U/L [12,13]. The milk also contains one protein that possesses many characteristics similar to human insulin [14]. One of the most unique properties of the camel milk is that, it is not affected by acidic environment and does not form coagulum in acidic environment such of the stomach [15]. This lack of coagulum formation allows the camel milk to pass rapidly through stomach together with the specific like protein/insulin and remains available for absorption in intestine. It was proposed that, this unique property of camel milk gives it the advantage to serve as a vehicle and a protector that facilitates the absorption of intact molecules of insulin by the small intestine [11]. This may be the reason for a lesser requirement of insulin in diabetic patients receiving camel milk. The therapeutic efficacy of camel milk observed in this study is consistent with earlier clinical trials conducted in humans to treat type $1 \mathrm{DM}$ with dromedaries' camel milk (camel milk+insulin therapy) $[16,17]$.

The dromedaries' camel milk has an anti-diabetic activity possibly because of insulin-like activity, regulatory and immuno-modulatory effect on beta cells $[5,6]$. The potential benefits of oral delivery of insulin include control of plasma glucose levels without peripheral hyper-insulinnaemia and restoration of the physiological pathway of endogenous insulin [5,6]. Delivery of therapeutic levels of insulin via the portal route decreases hyperinsulinaemia and more result in preservation of the counter regulatory responses to hypoglycaemia, with a concomitance reduction in hypoglycaemic events $[15,18,19]$ indicated that an addition of $5 \mathrm{mg}$ of oral insulin does not modify the course of the disease in the first year after diagnosis and probably does not statistically affect the humoral immune response against insulin.

The study also has revealed significant hypoglycemic effects of the dromedaries' camel milk when given an adjunctive to insulin therapy 
in type diabetic patients. The mean value of FBS for the entire study group before consumption of the camel milk was $286 \pm 108 \mathrm{mg} / \mathrm{dl}$ and after consumption of the camel milk it became $95 \pm 22 \mathrm{mg} / \mathrm{dl}$. Analysis of FBS for the study group before and after consumption of the camel milk has shown significant difference $(\mathrm{P}<0.0001)$. The results have shown a significant reduction in the FBS for the entire study group by $67 \%$ after consumption of the camel milk. The mean value of PPS for the entire study group before consumption of the camel milk was $(264 \pm 136) \mathrm{mg} / \mathrm{dl}$ and after consumption of the camel's milk it became $(93.5 \pm 17.5) \mathrm{mg} / \mathrm{dl}$. Statistical analysis of the PPS for the study group before and after consumption of the camel milk has shown significant difference $(\mathrm{P}<0.0001)$. The results have shown a reduction in the PPS by $65 \%$ for all the study group members after consumption of the camel milk. Results of the FBS and PPS for the study group were in contrast to the results of the FBS and PPS for the control group where reduction in the FBS and PPS has been achieved mainly due to increased parenteral insulin doses.

Significant improvements have been also observed in HbAlc levels in subjects received the camel milk (the study group). The mean value of the HbAlc for the entire study group before consumption of the camel milk was $(7.3 \pm 2.9) \%$ and after consumption of the camel milk it became $(4.6 \pm 1.5) \%$. Statistical analysis of the HbAlc values for the study group before and after consumption of the camel milk has shown significant difference $(\mathrm{P}<0.0001)$. The results have shown reduction in the $\mathrm{HbAlc}$ values for the study group by $37 \%$ since the second month of the camel's milk consumption. The significant effect of dromedary's camel milk in controlling hyperglycemia in subjects of the study group; might due to its high contents of insulin and ascorbic acid as well [19]. As mentioned previously, camel milk does not react to the acid and not form coagulum in acidic environment of the stomach [20,21]. Lack of coagulum formation of camel milk in acidic media and its antibacterial and antiviral activities might lie behind the efficacy of camel milk in the treatment of IDDM [22]. The decline in blood glucose followed camel milk consumption validates the fact that camel milk acts on regulating cellular sugar in the absence of endogenous insulin and in presence of exogenous oral insulin.

Dromedary's camel milk has been known for its high nutritional value $[5,6]$. Nutrition is essential for health maintenance and for the prevention of diseases. Camel's dromedaries' milk contains high levels of ascorbic acid (vitamin C) of 5.7-9.8\%, which is 3-5 times more than of other mammalian milks [20]. Camel milk is also rich in other vitamins such as B12, E, B1, B2 and A $[5,6]$. Camel milk has high concentrations of minerals such as calcium, iron, magnesium, cupper, manganese, sodium, phosphorus, zinc and potassium [6]. Lactose in camel milk, presents in average concentrations of $4.8 \%$, but this milk sugar is easily metabolized by persons suffering from lactose intolerance [6]. It is known that vitamins $\mathrm{A}, \mathrm{C}$ and $\mathrm{E}$ possess anti-oxidant properties and remove free radicals. Removal of free radicals by camel milk prevents tissues damage including the $\beta$-cells of the pancreas [23,24]. The high concentrations of antioxidants in camel milk and the effects of camel milk in lowering body fats in healthy individuals and in patients with IDDM $[5,6,25]$ might strengthen the insulin receptors to become more responsive to available insulin in camel milk.

\section{Conclusion}

In conclusion, this study has proven that, dromedary's camel milk works well in the regulation of blood sugar and in the improvement of carbohydrate metabolism in type 1 diabetic patients in the absence of original insulin when is given an adjuvant to insulin therapy. It seems that dromedary's camel milk works with the body's own restorative and regenerative abilities to overcome any metabolic aberrations in carbohydrate metabolism that might resulted from diabetes mellitus. Camel milk is well tolerated and it uses are not associated with any hypoglycemic risk and it can be used safely by diabetic patients on an empty stomach or after meals. Because of its high nutritional value, preventive and therapeutic qualities against DM and its complications, the authors recommend the usage of the dromedary's camel milk by healthy individuals, people at risk to diabetes and diabetic patients.

\section{Acknowledgements}

This work was supported partially by a research grant from Sudan Ministry of Higher Education and Scientific Research. The authors are thankful to Gadarif Health Insurance Fund for the permission to use their premises to do some of the FBS and PPS analyses free of charge and also they are thankful to Mrs. Amal Awad Aljeed for her assistance in following up with the patients. Also, we are thankful to Dr. Faiz Hamadelneel (King Khalid University, KSA) for his assistance to perform the statistical analysis.

\section{Conflict of Interests}

The authors declare that, they do not have any conflict of interest regarding this study.

\section{Author Contribution}

Abdalla $\mathrm{KO}$ conceived and designed the study and wrote the final manuscript. Ahmed A. Fadlalla conducted the clinical follow up of the patients in the clinic that include adjusting and prescribing the insulin doses for the patients. Also, Fadlalla AA contributed in the study design and in writing the final manuscript; both authors implemented the overall supervision and implementation of the study, its data collection and analysis. Both authors have read and approved the final version submitted.

\section{References}

1. World Health Organization 2012 Diabetes fact sheet No. 312 September.

2. Sboui A, Djegham M, Khorchani T, Hammadi M, Barhoumi K, et al. (2010) Effect of camel's milk on blood glucose, cholesterol and total proteins variations in alloxan-induced diabetic dogs. Int J Diab Metabol 18: 5-11.

3. Chaillous L, Carel JC, Thivolet C (1999) Lack of effect of one year oral insulin therapy in recent-onset type 1 diabetes: Results of a multi-centric randomized controlled trial. Diabetologia 42: A62- A62.

4. Abdalla KO (2016) Textbook: Fundamentals of Biological Chemistry. Lambert Academic Publishing OmniScriptum GmbH \& Co KG Germany. p: 172.

5. Abdalla KO (2016) Camel milk is an alternative and a complementary treatment to the current parenteral insulin therapy of insulin-dependent diabetes mellitus. Gezira Journal of Health Sciences 12: 65-87.

6. Abdalla KO (2014) An overview of the therapeutic effects of camel milk in the treatment of type 1 diabetes mellitus. Biomol Res Ther 3: 118.

7. Abdalla KO (2016) Scientific monograph: Treatment of incurable ailments with camel's milk and urine by scientific research. ISBN: 15-5-978-99942-64. Published by Sudan Ministry of Higher Education \& Scientific Research and International University of Africa in Sudan.

8. Abdalla KO (2015) Camel milk is an alternative and a complementary treatment to the current parenteral insulin therapy of type 1 diabetes mellitus. The 6th Annual Conference: The Medical \& Health Sciences Studies University of Khartoum.

9. American Diabetes Association (2012) Diabetes Care 35: S1.

10. Still JG (2002) Development of oral insulin: Progress and current status. Diabetes Metab Res Rev 18: S29-S37.

11. Kotb-El-SM, Al-Shoeibi ZY, Ahmed A, Zayed AA (2011) Effects of camel's milk as a vehicle for insulin on glycemic control and lipid profile in type 1 diabetes. American Journal of Biochemistry and Biotechnology 7: 179-189.

12. Singh R (2001) Annual Report of National Research Center on Camel. 1st edn. India. 50.

13. Hamad EM, Abdel-Rahim EA, Romeih EA (2011) Beneficial effect of camel milk on liver and kidneys function in diabetic Sprague-Dawley rats. Int $\mathrm{J}$ of Diary Science 6: 190-197.

14. Beg OU, Bahr-Lind HV, Zaidid ZH, Jhornvall H (1986) Characterization of a camel milk protein rich in proline identifies a new beta-casein fragment. Regul Pept 15: 55-61. 
Citation: Abdalla KO, Fadlalla AA (2018) Effects of Sudanese Dromedary's Camel Raw Milk on Insulin Doses and Carbohydrate Metabolism in Type 1 Diabetic Patients. J Biomol Res Ther 7: 159. doi:10.4172/2167-7956.1000159

Page 6 of 6

15. Davis SN, Dobbins R, Colburn C, Tarumi C, Jacobs J, et al. (1993) Effects of hyperinsulunemia in conscious dogs. American Journal of Physiology 264: E748-E755.

16. Agrawal RP, Beniwal R, Sharma S, Kochar DK, Tuteja FC, et al. (2005) Effect of raw camel milk in type 1 diabetic patients: 1 year randomized study. Journal of Camel Practice and Research 12: 27-35.

17. Agrawal PP, Swami SC, Beniwal R, Kochar DK, Sahani MS, et al. (2003) Effect of raw camel milk on glycemic control, risk factors and diabetes quality of life in type-1 diabetes: A randomised prospective controlled study. Journal of Camel Practice and Research 10: 45-50.

18. Wan CK, Giacca A, Matsuhisa M, Bahrani B, Lam L, et al. (2000) Increased response of glucagon and glucose production to hypoglycemia with intraperitoneal verses subcutaneous insulin treatment. Metabolism 49: 984-89.

19. Pozzilli P, Pitocco D, Visalli N, Cavallo MG, Buzzetti R, et al. (2000) No effect of oral insulin on residual beta-cell function in recent-onset Type I diabetes.
Diabetologia 43: 1000-4

20. Farahi Z, Retten MR, Atkins D (1992) Vitamin content of camel milk. Internat J Vit Nutr Res 62: 30-33

21. Wangoh J (1993) What steps towards camel milk technology. Int J Anim Sci 8: 9-11.

22. Lawrence RA, Lawrence RM (2010) Breastfeeding: A Guide for the Medical Professional. Elsevier-Health Sciences Division. p: 1114.

23. El-Agamy El, R Ruppanner, Ismail CP, Champagne, Assaf R (1992) Antibacterial and antiviral activity of camel milk protective proteins. J Diary Res 59: 169-175.

24. American Diabetes Association, 2010. Diagnosis and classification of diabetes mellitus. Diabetes Care 31: S55-S60.

25. Sudan Federal Ministry of Health 2012. Press release Alsahafa newspaper. 